\title{
Interest of systematic screening of pheochromocytoma in patients with neurofibromatosis type 1
}

\author{
Lori Képénékian', Thomas Mognetti², Jean-Christophe Lifante ${ }^{3}$, \\ Anne-Laure Giraudet ${ }^{2}$, Claire Houzard ${ }^{4}$, Stéphane Pinson ${ }^{5}$, \\ Françoise Borson-Chazot ${ }^{1}$ and Patrick Combemale ${ }^{6}$
}

'Department of Endocrinology and Diabetology, Hospices Civils de Lyon, Groupement Hospitalier Est, Hôpital Louis Pradel, Bron Cedex, France, ${ }^{2}$ Department of Nuclear Medicine, Léon Bérard Comprehensive Cancer Center, Lyon, France, ${ }^{3}$ Department of General, Digestive and Endocrine Surgery, Centre Hospitalier Lyon Sud, Université Claude Bernard Lyon 1, Pierre Bénite, France, ${ }^{4}$ Nuclear Medicine Unit, Imaging Department, Centre Hospitalier Lyon Sud, Pierre-Bénite, France, ${ }^{5}$ Molecular Genetics Laboratory, Hôpital Edouard Herriot, Bâtiment E, Lyon, France, and ${ }^{6}$ Rhône-Alpes Auvergne Competence Center for the treatment of Neurofibromatosis type 1, Léon Bérard Comprehensive Cancer Center, Lyon, France

Correspondence should be addressed to F Borson-Chazot Email

francoise.borson-chazot@ chu-lyon.fr

\begin{abstract}
Objective: Pheochromocytoma (PHEO) may occur in $0.1-5.7 \%$ of patients presenting with a neurofibromatosis type 1 (NF1). Current recommendations are to explore only symptomatic patients. The objective of the study is to evaluate the prevalence and the interest of a systematic PHEO screening in this population.

Design: A prospective study in a French tertiary center including consecutive NF1 patients older than 18 years.

Methods: A systematic screening combining abdominal imaging and urinary fractionated metanephrines was proposed. In case of positivity of one or both exams, ${ }^{123}$ I-metaiodobenzylguanidine scintigraphy or $\left[{ }^{18} \mathrm{~F}\right]$-fluoro-dihydroxyphenylalanine PET imaging was performed. The diagnosis of secreting PHEO was retained in case of elevated urinary metanephrines associated with positive scintigraphy and non-secreting PHEO when urinary metanephrines were normal with a positive scintigraphy.
\end{abstract}

Results: Between January 2014 and August 2015, 234 patients were included and 156 patients (66.7\%) completed both exams. In these 156 patients, 12 PHEOs were diagnosed, representing a prevalence of $7.7 \%$. Of these, six PHEOs were secreting, with only two symptomatic patients. The tumor size of these PHEOs were bigger than that of non-secreting PHEO ( $25.2 \pm 6.6$ vs $14 \pm 6.9 \mathrm{~mm}, \mathrm{P}=0.0165)$. One lesion was bilateral. Mean metanephrine and normetanephrine levels were $3.2 \pm 2.6 \mathrm{~N}$ and $2.8 \pm 1 \mathrm{~N}$ respectively. Three patients underwent surgery. The six patients with non-secreting PHEO were asymptomatic. One of them had bilateral lesion and one underwent surgery.

Conclusions: PHEO in NF1, whether or not secreting, are mostly asymptomatic. The current strategy to explore only symptomatic patients leads to an underestimation of prevalence with the risks inherent to the existence of an unrecognized PHEO.

\section{Introduction}

Neurofibromatosis type 1 (NF1), formerly named von Recklinghausen's disease, is a common inherited disorder with a prevalence of one case in 3000 births irrespective of sex or ethnic origin $(1,2)$. NF1 is an autosomal dominant condition with complete penetrance but an extremely
() 2016 European Society of Endocrinology Printed in Great Britain variable phenotype. The disease is caused by mutation in the NF1 gene (Ch 17), which is a classical tumor suppressor. The diagnosis is clinical with formal diagnostic criteria being published by the National Institutes of Health in 1987 (3) (Table 1). The main characteristic manifestations

Published by Bioscientifica Ltd. 
Table 1 National Institutes of Health (NIH) consensus criteria for diagnosis of neurofibromatosis type 1.

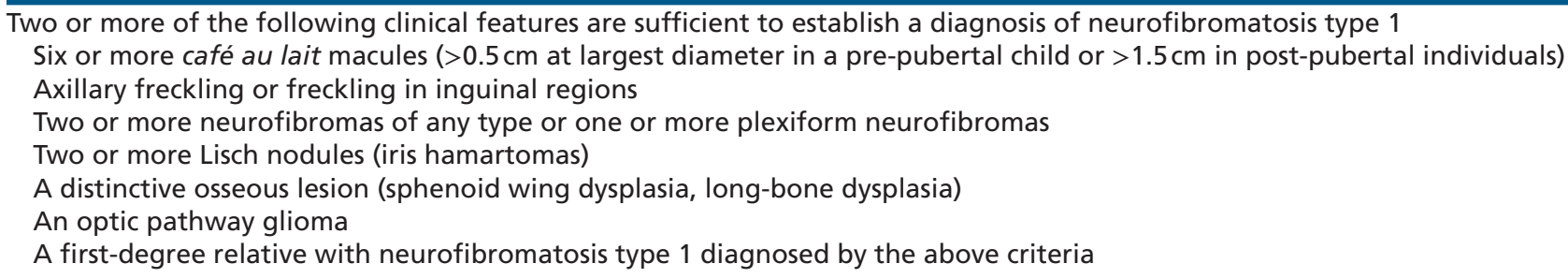

of NF1 are café au lait patches, neurofibromas (benign peripheral nerve sheath tumors), skin-fold freckling, iris Lisch nodules (hamartomas diagnosed on slit-lamp examination), and characteristic bony dysplasia of the long bones and sphenoid wing. Pheochromocytoma (PHEO), defined in 2004 by the World Health Organization as a tumor arising from adrenomedullary chromaffin cells that commonly produces one or more catecholamines (epinephrine, norepinephrine and dopamine) (4), is estimated to occur in $0.1-5.7 \%$ of patients with NF1 $(5,6)$. As it is a rare tumor, screening is not recommended in asymptomatic patients $(7,8)$. However, Zinnamosca et al. (9) in 2011 found a PHEO prevalence of $14 \%$ in a population of 48 consecutive NF1 patients, suggesting an underestimation of the prevalence of these lesions in this population. The objective of the study was to evaluate the prevalence and the interest of a systematic screening of PHEO in a NF1 population.

\section{Patients and methods}

\section{Patients}

This prospective single-center study including consecutive patients older than 18 years, consulting for NF1 since January 2014, was conducted in a regional competence center of NF1 (Centre Léon Bérard, Lyon, France). The study was performed according to French laws at the time of the initiation of the study and followed the principles laid down in the Declaration of Helsinki. Oral consent was obtained after a complete explanation of the protocol to the patients and was reported in the patient's medical record. Written consent was not specifically needed, as it was waived by the Centre Léon Bérard IRB, which approved this prospective study.

NF1 diagnosis was confirmed when patients met two or more of the seven criteria according to NIH consensus criteria (3). Blood pressure measured on both arms and symptoms as headaches, flushing, weakness, sweating, heart palpitations, weight loss, depression, and back pain were reported. Hypertension was defined as increased systolic blood pressure and diastolic blood pressure above 140 and $90 \mathrm{mmHg}$ respectively, or the use of antihypertension medication.

\section{Study design}

A systematic screening was suggested to patients, combining measurement of urinary fractionated metanephrines and imaging by abdominal computed tomography (CT) or abdominal ultrasound in nonoverweight patients $\left(\mathrm{BMI}<25 \mathrm{~kg} / \mathrm{m}^{2}\right)$ or in case of CT refusal. Plasma-free metanephrines was not measured due to the high cost of this procedure in a context of systematic screening. If ultrasound was abnormal or if both adrenal glands were not visible, a complementary abdominal CT was performed. In case of positivity of one or both exams, ${ }^{123}$ I-metaiodobenzylguanidine (MIBG) scintigraphy or $\left[{ }^{18} \mathrm{~F}\right]$-fluoro-dihydroxyphenylalanine $\left(\left[{ }^{18} \mathrm{~F}\right]\right.$-FDOPA) PET-CT was performed.

Quantification of urinary fractionated metanephrines was realized by Biomnis laboratory (Lyon, France) by high-performance liquid chromatography (HPLC). Results were considered positive when the rate of metanephrine (MA) and/or normetanephrine (NMA) was equal to or greater than twice normal $(2 \mathrm{~N}): 1500 \mathrm{nmol} / 24 \mathrm{~h}$ for $\mathrm{MA}$ and $2200 \mathrm{nmol} / 24 \mathrm{~h}$ for NMA before $01 / 05 / 2015$ and $228 \mathrm{nmol} / 24 \mathrm{~h}$ for MA and $213 \mathrm{nmol} / 24 \mathrm{~h}$ for NMA after 01/05/2015. 3-Ortho-methyldopamine was also quantified with a normal at $232 \mathrm{nmol} / 24 \mathrm{~h}$ and then at $320 \mathrm{nmol} / 24 \mathrm{~h}$ before and after 01/05/2015 respectively.

Abdominal ultrasound and CT were performed in various private radiology centers. Protocol of CT included sequences without and with contrast injection at arterial and portal time. When available, spontaneous density and contrast washout of the adrenal lesions were reported.

\section{Scintigraphy protocol}

The first patients included in the study underwent

${ }^{123}$ I-MIBG scintigraphy and, as soon as $\left[{ }^{18} \mathrm{~F}\right]$-FDOPA 
PET-CT became available, the PET-CT was preferred for the following reasons: higher resolution, no necessity of thyroid blockage and interruption of antihypertension medication, and 1-day procedure.

${ }^{123}$ I-MIBG acquisitions were performed on Tandem Discovery NM/CT 670 from GE Healthcare Systems (Milwaukee, US) $24 \mathrm{~h}$ after injection of $370 \mathrm{MBq}$ of iobenguane sulfate i-123 (AdreView, GE Healthcare, Medi-Physics, Inc, Arlington Heights, IL, USA). Planar $13.3 \mathrm{~cm} / \mathrm{min}$ speed whole-body acquisition was followed by a SPECT/CT acquisition centered on the upper abdomen ( 60 frames, 15 -s projections were acquired over $360^{\circ}, 128 \times 128$ Matrix, MEGP/PARA collimator grid, $40 \times 54 \mathrm{~cm} \mathrm{FOV)}$.

$\left[{ }^{18} \mathrm{~F}\right]$-FDOPA PET-CT acquisition started $1 \mathrm{~h}$ after intravenous injection of $3 \mathrm{MBq} / \mathrm{kg}$ of ${ }^{18} \mathrm{~F}$-DOPA (IASOdopa, from Advanced Accelerator Applications (AAA) France). No iodinated contrast material was administered. PET-CT was performed using the same protocol for every patient on a GEMINI TF 16 or TEP GEMINI TF16 BIG BORE (Philips Healthcare) from the top of the head to mid-thighs.

\section{Criteria used for diagnosis of pheochromocytoma}

The diagnosis of secreting PHEO was retained in case of elevated urinary metanephrines (MA and/or NMA $\geq 2 \mathrm{~N}$ ) associated with positive scintigraphy, and non-secreting PHEO when urinary metanephrines were both normal with a positive scintigraphy.

\section{Surgery and pathological examination}

Patients with secreting PHEO underwent laparoscopic surgery in the University Hospital of Lyon Sud. Medical preparation included 15 days of calcium channel blockers (nicardipine $50 \mathrm{mg}$ twice a day) and regimen rich in sodium. In per-operative period, blood pressure and heart rate were digitally recorded automatically and continuously via a catheter in the radial artery. Every attempt was made to clip-ligate the main adrenal vein early during laparoscopic adrenalectomy, before manipulating the adrenal tumor. Undesirable blood pressure elevations during surgery were treated with iv nicardipine. Undesirable heart rate elevations were treated with i.v. beta blockers. Immediately after tumor removal, glycemia monitoring was realized because of the risk of severe hypoglycemia. All patients were reexamined within
1 month post-operatively. Patients with only secreting PHEO and non-secreting PHEO with a tumor size higher than $2 \mathrm{~cm}$ underwent surgery. The others were followed every 6 months with urinary fractionated metanephrines and abdominal CT.

It is not possible to determine malignancy by histological evaluation. However, pathology criteria such as size, weight, presence of tumor necrosis, capsular invasion, Ki-67 index greater than $4 \%$, and absence of PS100, which are linked to a greater risk of malignancy (10), were reported.

\section{Statistical analysis}

Data are given as mean \pm S.D. and median (range) and analyzed using unpaired Student's $t$-test. Differences were considered statistically significant at $P<0.05$. Pearson's correlation coefficient was applied to analyze the correlation between tumor size and metanephrine secretion in secreting PHEO.

\section{Results}

Between January 2014 and August 2015, 234 patients were included. Characteristics of patient population are presented in Table 2.

Overall, 156 patients completed the two exams, representing $66.7 \%$ of patients. Of these 156 patients, 12 PHEOs were diagnosed, giving a prevalence of $7.7 \%$ : six secreting PHEOs and six non-secreting PHEOs (Fig. 1).

Table 2 Characteristics of patient population.

\begin{tabular}{|c|c|c|}
\hline & $\begin{array}{c}\text { All patients } \\
(n=234)\end{array}$ & $\begin{array}{l}\text { Patients with full screening } \\
\qquad(n=156)\end{array}$ \\
\hline Sex ratio (H/F) & $98 / 136$ & $75 / 81$ \\
\hline \multicolumn{3}{|l|}{ Age (years) } \\
\hline $\begin{array}{l}\text { mean } \pm \text { S.D. } \\
\text { median (range) }\end{array}$ & $\begin{array}{c}41.3 \pm 14 \\
38(18-79)\end{array}$ & $\begin{array}{c}43.9 \pm 14^{*} \\
42.5(18-77)\end{array}$ \\
\hline Hypertension $(n(\%))$ & $28(12 \%)$ & $21(13.5 \%)$ \\
\hline $\begin{array}{l}\text { Urinary fractionated } \\
\text { metanephrines }\end{array}$ & 177 & 156 \\
\hline Abdominal imaging & 178 & 158 \\
\hline $\mathrm{CT}$ & 149 & 136 \\
\hline Ultrasound & 29 & 22 \\
\hline Scintigraphy & 23 & 23 \\
\hline${ }^{123}$ I-MIBG & 4 & 4 \\
\hline$\left[{ }^{18} \mathrm{~F}\right]-\mathrm{FDOPA}$ & 19 & 19 \\
\hline
\end{tabular}

$\left[{ }^{18} \mathrm{~F}\right]-$ FDOPA, $\left[{ }^{18} \mathrm{~F}\right]$-fluoro-dihydroxyphenylalanine PET imaging; ${ }^{123}$-MIBG, ${ }^{123}$-metaiodobenzylguanidine scintigraphy; $\mathrm{CT}$, computed tomography. $* P=0.06$ for the comparison by unpaired Student's $t$-test with all patients group. 
234 patient

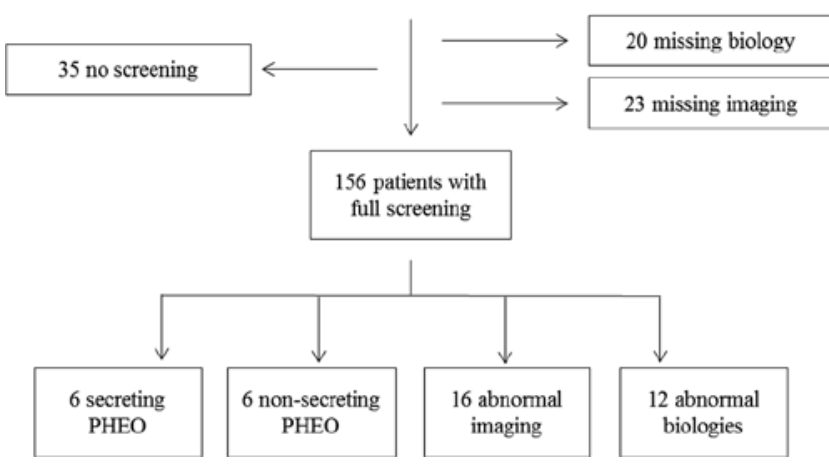

Figure 1

Flowchart. PHEO, pheochromocytoma.

\section{Patients with pheochromocytoma}

Characteristics of patients with secreting and nonsecreting PHEO are reported in Table 3.

Age at diagnosis was not different between both groups $(55.3 \pm 13.7$ for secreting PHEO vs $53.2 \pm 15.9$ for nonsecreting PHEO, $P=0.805)$, but was significantly greater in patients with secreting PHEO than in screened patients with negative explorations $(55.3 \pm 13.7$ vs $43.1 \pm 13.9$, $P=0.036)$. The difference was not significant for nonsecreting PHEO $(53.2 \pm 15.9$ vs $43.1 \pm 13.9, P=0.086)$.

Only two patients with secreting PHEO had symptoms at diagnosis: one underwent a treatment for hypertension with blood pressure up to $180 / 80 \mathrm{mmHg}$, which did not regress after surgery. The other patient had paroxysmal hypertension with headaches for the past few years, with blood pressure of 160/100 $\mathrm{mmHg}$ at annual visit.

Tumor size of secreting PHEO was significantly higher than that of non-secreting PHEO $(25.2 \pm 6.6$ vs $14 \pm 6.9 \mathrm{~mm}, P=0.0165)$ as well as NMA secretion $(2.8 \pm 1 \mathrm{~N}$ vs $0.75 \pm 0.1 \mathrm{~N}, P=0.0008)$. However, no correlation was found between tumor size and metanephrine secretion in secreting PHEO (Fig. 2).

There were two bilateral PHEOs (16.6\% of PHEO): one synchronous secreting PHEO (patient 1) and one metachronous non-secreting PHEO (patient 7) with a previous secreting PHEO treated by surgery in 1985. One patient with secreting PHEO (patient 3) had a contralateral adenoma (12 mm, spontaneous density $5 \mathrm{UH}$, washout $66 \%$ ).

\section{Abnormal biology}

Twelve (7.2\%) patients presented an isolated elevation of urinary fractionated metanephrines without abnormalities at imaging. In two cases, 3-ortho-methyldopamine was increased (first one at $1.4 \mathrm{~N}$ and the second at $6.7 \mathrm{~N}$ but in a context of vaso-vagal episode with normal result at further control). In the ten others, NMA was moderately increased at $1.4 \pm 0.2 \mathrm{~N}$ as a mean. Medications were identified as a confounding factor in four patients ( $\beta$-adrenergic receptor blockers and tricyclic antidepressant). The others had normal results at subsequent determination.

\section{Abnormal imaging}

Sixteen (9.7\%) abnormal imaging were incidentally diagnosed: four gastrointestinal stromal tumor (GISTs); two unilateral adrenal hyperplasia; one bilateral adrenal hyperplasia; three extra-adrenal nodules with one renal oncocytoma and two neurofibromas; and six adrenal nodules including one myolipoma, three adenomas (spontaneous density $<10 \mathrm{UH}$, washout $>60 \%$ ) and two unspecified nodules.

Patient characteristics with GIST were as follows: three men and one woman, age at diagnosis $50 \pm 12$ years, asymptomatic, localized to the small intestine, and tumor size $55.5 \pm 3.3 \mathrm{~mm}$. Three patients underwent surgery, the last patient had only biopsy because he was contraindicated for surgery, and two of them had adjuvant treatment by imatinib. All tumors were negative for KIT and PDGFRA.

\section{Scintigraphy}

In total, 23 scintigraphies were performed in 22 patients: three patients underwent ${ }^{123}$ I-MIBG scintigraphies, 18 patients $\left[{ }^{18} \mathrm{~F}\right]$-FDOPA PET-CT and one patient both examinations.

The four patients submitted to ${ }^{123}$ I-MIBG presented with elevated urinary metanephrines. ${ }^{123}$ I-MIBG scintigraphy was positive in two patients with a secreting PHEO, visualized by CT and histologically proven after tumor resection (patients 3 and 6). In patient 6 , catecholamine secretion was symptomatic with a treated hypertension. In patient 3, ${ }^{123}$ I-MIBG was considered positive in a $25 \mathrm{~mm}$ adrenal lesion observed on CT.

From the 19 [ $\left.{ }^{18} \mathrm{~F}\right]-F D O P A$ PET-CT, ten were positive leading to the diagnosis of $\mathrm{PHEO}$, including four secreting PHEOs (patients 1, 2, 4 and 5) and the six non-secreting PHEOs. All patients with a positive scintigraphy had an adrenal lesion on abdominal CT. The nine remaining examinations were negative. 
Table 3 Characteristics of patients with secreting and non-secreting pheochromocytoma.

\begin{tabular}{|c|c|c|c|c|c|c|c|c|}
\hline \multirow[b]{2}{*}{ Patient } & \multirow[b]{2}{*}{ Sex } & \multirow{2}{*}{$\begin{array}{l}\text { Age at } \\
\text { diagnosis } \\
\text { (years) }\end{array}$} & \multirow[b]{2}{*}{ Symptoms } & \multicolumn{2}{|c|}{$\begin{array}{c}\text { Urinary fractionated } \\
\text { metanephrines }\end{array}$} & \multirow{2}{*}{$\begin{array}{c}\text { Tumor size } \\
\text { on } \mathbf{C T} \\
(\mathrm{mm})\end{array}$} & \multirow[b]{2}{*}{ Scintigraphy } & \multirow[b]{2}{*}{ NF1 manifestations } \\
\hline & & & & MA (N) & NMA (N) & & & \\
\hline \multicolumn{9}{|c|}{ Secreting pheochromocytoma } \\
\hline 1 & $\mathrm{~F}$ & 54 & $\begin{array}{l}\text { HTN, } \\
\text { headache }\end{array}$ & 1.0 & 3.6 & 16 & {$\left[{ }^{18} \mathrm{~F}\right]-\mathrm{FDOPA}$} & $\begin{array}{l}\text { TCL, SFF, C-NF, learning } \\
\text { difficulties }\end{array}$ \\
\hline 2 & $\mathrm{~F}$ & 53 & None & 1.4 & 2.4 & 19 & {$\left[{ }^{18} \mathrm{~F}\right]-\mathrm{FDOPA}$} & $\begin{array}{l}\text { TCL, C-NF, pseudarthrosis, } \\
\text { P-NF, learning } \\
\text { difficulties }\end{array}$ \\
\hline 3 & $\mathrm{M}$ & 77 & None & 2.0 & 2.1 & 25 & ${ }^{123} \mathrm{I}-\mathrm{MIBG}$ & $\begin{array}{l}\text { TCL, C-NF, scoliosis, } \\
\text { vertebral dysplasia, } \\
\text { basocellular } \\
\text { carcinoma }\end{array}$ \\
\hline 4 & $\mathrm{M}$ & 34 & None & 4.9 & 1.2 & 30 & {$\left[{ }^{18} \mathrm{~F}\right]-\mathrm{FDOPA}$} & $\begin{array}{l}\text { TCL, SSF, C-NF and SC-NF } \\
\text { with nerve compression, } \\
\text { optic pathway glioma }\end{array}$ \\
\hline 5 & $\mathrm{M}$ & 57 & None & 2.0 & 3.4 & 28 & {$\left[{ }^{18} \mathrm{~F}\right]-\mathrm{FDOPA}$} & $\begin{array}{l}\text { TCL, SFF, C-NF, P-NF, Lisch } \\
\text { nodules, UBOs }\end{array}$ \\
\hline 6 & $\mathrm{M}$ & 57 & HTN & 7.6 & 3.9 & 33 & 123I-MIBG & $\mathrm{TCL}, \mathrm{SFF}, \mathrm{C}-\mathrm{NF}$ \\
\hline $\begin{array}{l}\text { Total } \\
\text { (mean } \pm \text { s.D.) }\end{array}$ & - & $55.3 \pm 13.7$ & - & $3.2 \pm 2.6$ & $2.8 \pm 1$ & $25.2 \pm 6.6$ & - & \\
\hline \multicolumn{9}{|c|}{ Non-secreting pheochromocytoma } \\
\hline 7 & $\mathrm{~F}$ & 51 & None & 0.4 & 0.8 & 6 & {$\left[{ }^{18} \mathrm{~F}\right]-\mathrm{FDOPA}$} & $\begin{array}{l}\text { Lisch nodules, P-NF, } \\
\text { PHEO, jejunal GIST }\end{array}$ \\
\hline 8 & $\mathrm{~F}$ & 60 & None & 1.0 & 0.8 & 15 & {$\left[{ }^{18} \mathrm{~F}\right]-\mathrm{FDOPA}$} & $\begin{array}{l}\mathrm{TCL}, \mathrm{SFF}, \mathrm{C}-\mathrm{NF}, \\
\text { polyneuropathy }\end{array}$ \\
\hline 9 & $\mathrm{~F}$ & 61 & None & 1.0 & 0.9 & 26 & {$\left[{ }^{18} \mathrm{~F}\right]-\mathrm{FDOPA}$} & SFF, C-NF, P-NF, MPNST \\
\hline 10 & $\mathrm{~F}$ & 35 & None & 0.9 & 0.6 & 11 & {$\left[{ }^{18} \mathrm{~F}\right]-\mathrm{FDOPA}$} & TCL, SFF, C-NF, P-NF \\
\hline 11 & $\mathrm{~F}$ & 76 & None & 0.9 & 0.7 & 16 & {$\left[{ }^{18} \mathrm{~F}\right]-\mathrm{FDOPA}$} & TCL, SFF, C-NF and SC-NF \\
\hline 12 & $\mathrm{~F}$ & 36 & None & 0.8 & 0.7 & 10 & {$\left[{ }^{18} \mathrm{~F}\right]-\mathrm{FDOPA}$} & $\begin{array}{l}\text { TCL, SFF, C-NF and SC-NF, } \\
\text { P-NF with congenital } \\
\text { glaucoma }\end{array}$ \\
\hline $\begin{array}{l}\text { Total } \\
\text { (mean } \pm \text { s.D.) }\end{array}$ & - & $53.2 \pm 15.9 *$ & - & $0.85 \pm 0.2 * *$ & $0.75 \pm 0.1 * * *$ & $14 \pm 6.9 * * * *$ & - & \\
\hline
\end{tabular}

C-NF, cutaneous neurofibroma; CT, computed tomography; HTN, high blood pressure; MA, metanephrine ( $\mathrm{N}=1500 \mathrm{nmol} / 24 \mathrm{~h})$; MPNST, malignant peripheral nerve sheath tumor; NMA, normetanephrine ( $\mathrm{N}=2200 \mathrm{nmol} / 24 \mathrm{~h}) ; \mathrm{P}-\mathrm{NF}$, plexiform neurofibroma; SC-NF, sub-cutaneous neurofibroma; SFF, skin-fold freckling; TCL, café au lait patches; UBOs, unidentified bright objects at MRI.

${ }^{*} P=0.805,{ }^{*} P=0.055, * * * P=0.0008$ and $* * * P=0.0165$ for the comparison by unpaired Student's $t$-test with secreting pheochromocytoma. Patient 6 and patient 8 had beta blocker treatment.

Six were realized because of adrenal lesion at abdominal CT and three because of elevated urinary metanephrines. From the four secreting PHEOs, one symptomatic patient (patient 1 ) demonstrated an intense ${ }^{18} \mathrm{~F}$-DOPA uptake in a $16 \mathrm{~mm}$ nodule on the left adrenal gland and a lower tracer uptake in an $8 \mathrm{~mm}$ thick right adrenal gland nodule suggesting a bilateral PHEO (Fig. 3). Concerning non-secreting PHEO, three patients demonstrated intense ${ }^{18} \mathrm{~F}$-DOPA uptake in adrenal lesions sizing 11 , 16 and $26 \mathrm{~mm}$ (patients 10,11 and 9 respectively). The lesion of $26 \mathrm{~mm}$ in patient 9 has been removed and corresponds with a PHEO.

In none of the patients, the scintigraphy examination found abnormal tracer uptake outside the adrenal glands that could be consistent with ectopic PHEO.

\section{Surgery}

Three patients with secreting PHEO underwent surgery after medical preparation (patients 2, 3 and 6) and one patient with non-secreting PHEO because of tumor size $>2 \mathrm{~cm}$ (patient 9). There were no per- or postoperative complications, and all urinary fractionated metanephrines were normalized after surgery in secreting PHEO. The post-operative follow-up duration was 15,6 , 24 and 3 months respectively. Surgery is also planned for patient 1 and is under consideration for patients 4 and 5 . Three PHEOs presented one criteria of aggressivity at pathological examination with capsular invasion, and the last one presented two criteria with one atypical mitotic figure and adipose tissue invasion. Ki- 67 was $<1 \%$ in all 

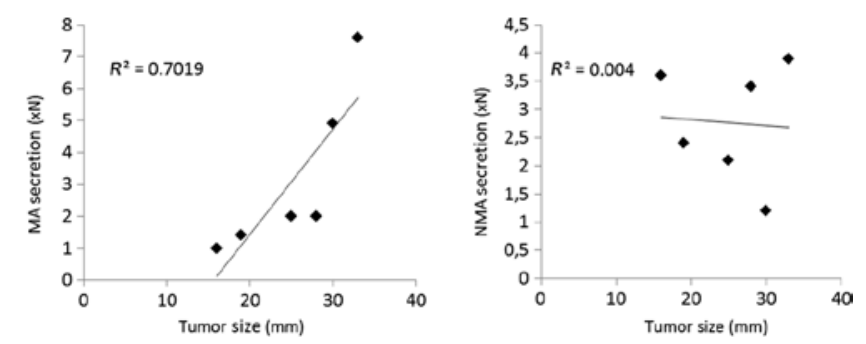

\section{Figure 2}

Correlation between tumor size and metanephrines secretion of secreting pheochromocytoma. MA, metanephrine $(\mathrm{N}=1500 \mathrm{nmol} / 24 \mathrm{~h}) ; \mathrm{NMA}$, normetanephrine $(\mathrm{N}=2200 \mathrm{nmol} / 24 \mathrm{~h}) ; R^{2}$, Pearson correlation coefficient.

cases. The other patients with non-secreting PHEO did not undergo surgery because of small tumor size, $<2 \mathrm{~cm}$.

\section{Discussion}

In this study, the prevalence of PHEO in NF1 patients was found to be $7.7 \%$, which is well above that reported in previous studies $(5,6)$. This may be, at least partly, explained by the lack of symptoms (84\% of asymptomatic PHEO) and the non-secreting nature of a large part of detected PHEO (50\%), already described in 2013 by Haissaguerre et al. (11) in a retrospective study performed in sporadic PHEO.

In the literature, the age at onset of PHEO is typically the fourth decade of life, both in NF1associated and sporadic cases (12, 13), without influence of gender. In our study, age at diagnosis is a little bit higher, at $55.3 \pm 13.7$ years, for secreting PHEO and $53.2 \pm 15.9$ years for non-secreting PHEO, without significant difference. However, as a large part of
PHEO is asymptomatic and/or non-secreting, diagnosis is probably delayed.

In a study in 2006, conducted on a large European registry of patients with PHEO, including 25 NF1 patients, Bausch et al. (14) found bilateral PHEO in 20\% of NF1 patients, all were adrenal originated without ectopic PHEO and 12\% were malignant (presence of metastases). The characteristics of patients with PHEO related to NF1 were similar to those of patients with sporadic PHEO except for multifocal localization and malignancy. Our results are somewhat different with two cases of bilateral PHEO (16.6\% of diagnosed PHEO) and no malignancy, but all diagnosed PHEO were adrenal too. However, the study population was not the same, and our follow-up duration was probably too short to diagnose metastases.

It has been reported that the amounts of catecholamines released by secreting PHEO resulting in hypertension were positively correlated with their size $(15,16)$. In this study, tumor size of secreting PHEO was significantly higher than that of non-secreting PHEO, but there was no correlation between metanephrine secretion and tumor size of secreting PHEO. However, only two out of the six patients with a secreting PHEO presented with hypertension. All of them secreted MA and/or NMA, as it is classically reported in NF1 patients (17).

Concerning biochemical testing for diagnosis of PHEO, the Endocrine Society recommends that initial biochemical testing should include measurements of plasma-free metanephrines or urinary fractionated metanephrines (7). Indeed, as shown by Perry et al. (18), measurement of urinary fractionated metanephrines by mass spectrometry provides excellent sensitivity (97\%) and specificity (91\%) for diagnosis of PHEO. Plasmafree metanephrine measurement has been reported to have better performances than urinary fractionated

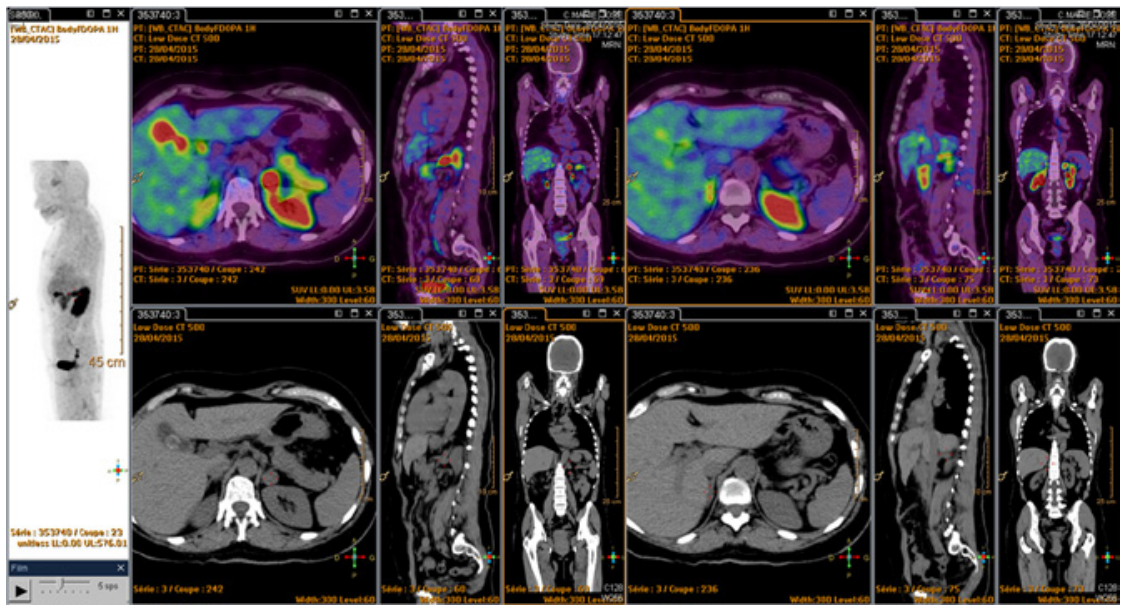

Figure 3

$\left[{ }^{18} \mathrm{~F}\right]-\mathrm{FDOPA}$ PET of patient 1 with bilateral secreting pheochromocytoma. A full color version of this figure is available at http://dx.doi.org/10.1530/EJE-16-0233. 
metanephrines, especially better sensitivity (19). However, it is more expansive, not reimbursed in all countries and less available, which could be problematic in a systematic screening approach. We have chosen a threshold of $2 \mathrm{~N}$ for secreting PHEO to eliminate the false positives and improve the sensivity of screening since we were in a systematic screening approach. All patients with MA and/or NMA $>2 \mathrm{~N}$ were diagnosed with a secreting PHEO and all false positives were $<1.5 \mathrm{~N}$, essentially with isolated elevated NMA. In most cases, this was explained by essential hypertension and medications as beta blockers and tricyclic antidepressants $(20,21)$.

Anatomical imaging performed in this study was abdominal ultrasound in non-overweight patients $\left(\mathrm{BMI}<25 \mathrm{~kg} / \mathrm{m}^{2}\right)$ or in case of CT refusal, and abdominal $\mathrm{CT}$ in the others or in case of abnormal abdominal ultrasound. CT is recommended as the first-choice imaging modality for the localization of PHEO and paraganglioma (7) because of its excellent spatial resolution for thorax, abdomen and pelvis with sensitivity between 88 and $100 \%$ $(22,23,24)$. Moreover, $20 \%$ of PHEO and paraganglioma is revealed by acute emergency situation with endorgan damage. In these cases, biochemical diagnosis of PHEO suffers drawbacks because of delays in provision of results and false positive in such form of stress; that is why abdominal CT is more appropriate to locate a tumor and to adapt therapeutic management (25). However, in a systematic screening approach, ultrasound could be considered as a less invasive examination, with correct performances. According to Krawjeska et al. (26), its specificity considering adrenal gland evaluation is estimated at 92\%, whereas its sensitivity is estimated at $76 \%$, lower in case of left-sided tumors, those $<2 \mathrm{~cm}$ in diameter, and in obese patients. In this study, two out of the 27 ultrasounds were positive - one case of secreting PHEO (patient 2) and one case of non-secreting PHEO (patient 7).

Concerning functional imaging, patients with elevated urinary fractionated metanephrines and/or a lesion at abdominal CT underwent a scintigraphy. Sensitivity of ${ }^{123}$ I-MIBG scintigraphy ranges between 85 and $88 \%$ for PHEO, whereas specificity ranges from 70 to $100 \%(27,28)$. In a meta-analysis of 15 studies of ${ }^{123}$ I-MIBG scintigraphy, sensitivity was $94 \%$ and specificity was 92\% (29). Newer compounds such as $\left[{ }^{18} \mathrm{~F}\right]$-FDOPA PET-CT have been described to outperform ${ }^{123}$ I-MIBG scintigraphy in the detection of PHEO, with a sensitivity of $100 \%$ for $\left[{ }^{18} \mathrm{~F}\right]-F D O P A$ PET-CT and $71 \%$ for ${ }^{123}$ I-MIBG scintigraphy $(22,30,31)$, particularly in paraganglioma and metastatic disease.
Moreover, $\left[{ }^{18} \mathrm{~F}\right]$-FDOPA PET-CT has other advantages no necessity of thyroid blockage and interruption of antihypertension medication, and only 1-day procedure. This could be a bias in our study, as smaller lesions could be better diagnosed with $\left[{ }^{18} \mathrm{~F}\right]$-FDOPA PET-CT than with ${ }^{123}$ I-MIBG scintigraphy. However, only four ${ }^{123}$ I-MIBG scintigraphies were performed (including one patient with both examinations) vs $19\left[{ }^{18} \mathrm{~F}\right]$-FDOPA PET-CT, and two of them have been conducted to diagnose PHEO.

Concerning peri-operative medical management, the US Endocrinology Society suggests $\alpha$-adrenergic receptor blockers as the first choice. However, some studies have suggested that the use of calcium blockers was safe and associated with a low morbidity and mortality $(32,33,34)$.

The main limitations of our work is the lack of urinary creatinine measurement to verify the completeness of the urine collection for urinary fractionated metanephrine evaluation, and the lack of standardization of abdominal CT protocol, as examinations were realized in different radiology centers. Nevertheless, radiologists were informed to explore adrenal glands. As expected, our approach had led us to the diagnosis of several adrenal incidentalomas. Their prevalence was rather high $-9.7 \%-$ compared with that usually reported in the general population from radiological series (between 0.3 and $4.4 \%)(32,33)$, raising the question of follow-up to apply. We also incidentally diagnosed a GIST in four patients without PHEO, corresponding to $1.7 \%$ of patients. This is not surprising as GISTs are known to occur in patients with NF1 with a prevalence estimated between 4 and 25\% $(34,35)$. All patients were asymptomatic, as it is classically observed with only $5 \%$ of symptomatic cases (36); no expression of KIT and PDGFRA was found (37).

Nevertheless, in this study, systematic screening led to the diagnosis of 12 PHEO. Only two of them would have been diagnosed using the conventional strategy to explore only symptomatic patients. It is crucial to identify these tumors for several reasons (7). First, PHEOs are classically recurrent in genetic syndrome, including NF1, with a proportion between 10 and 20\% $(9,12,14)$. Therefore, adrenocortical sparing surgery represents a major concern and has gained popularity in the last few years in various indications $(38,39$, 40). First, this technique could be applied only in case of small lesion (usually smaller than $2 \mathrm{~cm}$ ), hence the importance of early diagnosis. Secondly, even if it is rare, PHEO may have a malignant potential, defined as the presence of metastases in nonchromaffin tissue (41). Discordant results have been reported on the prevalence 
of malignant PHEO in NF1. In large series, the metastatic potential of PHEO was estimated to be around 10\% $(12,14)$. By contrast, Zinnamosca et al. in 2011 (9) found no malignant PHEO in a small series of 48 patients. Finally, as observed in this study, secreting PHEO can be asymptomatic. Lafont et al. (42) demonstrated in a cohort of 50 patients that normotensive PHEO have roughly comparable per-operative hemodynamic instability to hypertensive PHEO and differ markedly from non-PHEO adrenal incidentalomas. It is therefore crucial to identify normotensive PHEO when surgery is scheduled and to apply the standard of care for PHEO anesthesia. Surprisingly, we found in this series that $50 \%$ of PHEO was not secreting. A patient with a large PHEO more than $2 \mathrm{~cm}$ underwent surgery, but the others were followed on. The natural history of these PHEO is not well known and whether these non-secreting tumors will become secreting, rapidly progressive, or at risk of malignancy remains to be determined to clearly assess the cost-benefit ratio of such a strategy and the modalities of the follow-up. For now, we would suggest performing screening every $4-5$ years after 40 years of age.

This is the biggest prospective study of prevalence of PHEO in patients with NF1. Our results suggest a clear underestimation with a prevalence classically evaluated at $1 \%$ vs $7.7 \%$ in our study, explaining all the consensus recommending screening only symptomatic patients $(7,8$, 43). The large part of non-secreting PHEO, usually scarce, raises the question of the treatment and the follow-up to achieve. Some elements suggest an interest of diagnosis of these non-secreting PHEO, as we discussed earlier, with medical preparation in case of other surgery to prevent peroperative complications, and to initiate a follow-up of these lesions. However, the benefit of this strategy is not clearly demonstrated, especially concerning the cost/benefit aspect.

In conclusion, PHEO in NF1, whether or not secreting, are often asymptomatic. The current strategy to explore only symptomatic patients leads to an underestimation of prevalence with the risks inherent to the existence of unrecognized PHEO. Therefore, PHEO screening may be proposed to all NF1 patients older than 40 years, with metanephrine quantitative analysis and imaging based on CT or MRI to lower patient irradiation. Further studies are needed to assess this proposition, the evolution of these lesions, in particular non-secreting lesions, and their therapeutic management.

\section{Declaration of interest}

The authors declare that there is no conflict of interest that could be perceived as prejudicing the impartiality of the research reported.

\section{Funding}

This research did not receive any specific grant from any funding agency in the public, commercial or not-for-profit sector.

\section{References}

1 Lammert M, Friedman JM, Kluwe L \& Mautner VF. Prevalence of neurofibromatosis 1 in German children at elementary school enrollment. Archives of Dermatology 2005141 71-74. (doi:10.1001/ archderm.141.1.71)

2 Huson SM, Harper PS \& Compston DA. Von Recklinghausen neurofibromatosis. A clinical and population study in south-east Wales. Brain: A Journal of Neurology 198811 1355-1381. (doi:10.1093/brain/111.6.1355)

3 National Institutes of Health Consensus Development Conference Statement. Neurofibromatosis 19881 172-178.

4 Pacak K \& Del Rivero J. Pheochromocytoma. In Endotext. Eds LJ De Groot, P Beck-Peccoz, G Chrousos, K Dungan, A Grossman, JM Hershman, C Koch, R McLachlan, M New, R Rebar et al. South Dartmouth, MA, USA: MDText.com, Inc., 2000.

5 Opocher G \& Schiavi F. Genetics of pheochromocytomas and paragangliomas. Best Practice \& Research. Clinical Endocrinology \& Metabolism 201024 943-956. (doi:10.1016/ j.beem.2010.05.001)

6 Bryant J, Farmer J, Kessler LJ, Townsend RR \& Nathanson KL. Pheochromocytoma: the expanding genetic differential diagnosis. Journal of the National Cancer Institute 200395 1196-1204. (doi:10.1093/jnci/djg024)

7 Lenders JWM, Duh Q-Y, Eisenhofer G, Gimenez-Roqueplo A-P, Grebe SKG, Murad MH, Naruse M, Pacak K, Young WF \& Endocrine Society. Pheochromocytoma and paraganglioma: an endocrine society clinical practice guideline. Journal of Clinical Endocrinology and Metabolism 201499 1915-1942. (doi:10.1210/ jc.2014-1498)

8 Pinson S, Créange A, Barbarot S, Stalder JF, Chaix Y, Rodriguez D, Sanson M, Bernheim A, D'incan M, Doz F et al. [Neurofibromatosis 1: recommendations for management]. Annales de Dermatologie et de Vénéréologie 2001128 567-575.

9 Zinnamosca L, Petramala L, Cotesta D, Marinelli C, Schina M, Cianci R, Giustini S, Sciomer S, Anastasi E, Calvieri S et al. Neurofibromatosis type 1 (NF1) and pheochromocytoma: prevalence, clinical and cardiovascular aspects. Archives of Dermatological Research 2011303 317-325. (doi:10.1007/s00403-010-1090-z)

10 de Wailly P, Oragano L, Radé F, Beaulieu A, Arnault V, Levillain P \& Kraimps JL. Malignant pheochromocytoma: new malignancy criteria. Langenbeck's Archives of Surgery/Deutsche Gesellschaft Für Chirurgie 2012 397 239-246. (doi:10.1007/s00423-011-0850-3)

11 Haissaguerre M, Courel M, Caron P, Denost S, Dubessy C, Gosse P, Appavoupoulle V, Belleannée G, Jullié M-L, Montero-Hadjadje M et al. Normotensive incidentally discovered pheochromocytomas display specific biochemical, cellular, and molecular characteristics. Journal of Clinical Endocrinology and Metabolism 201398 4346-4354. (doi:10.1210/jc.2013-1844)

12 Walther MM, Herring J, Enquist E, Keiser HR \& Linehan WM. von Recklinghausen's disease and pheochromocytomas. Journal of Urology 1999162 1582-1586. (doi:10.1016/S0022-5347(05)68171-2)

13 Plouin P-F \& Gimenez-Roqueplo A-P. Pheochromocytomas and secreting paragangliomas. Orphanet Journal of Rare Diseases 2006149. (doi:10.1186/1750-1172-1-49)

14 Bausch B, Borozdin W, Neumann HPH \& European-American Pheochromocytoma Study Group. Clinical and genetic characteristics of patients with neurofibromatosis type 1 and pheochromocytoma. New England Journal of Medicine 2006354 2729-2731. (doi:10.1056/ NEJMc066006) 
15 Eisenhofer G, Lenders JWM, Goldstein DS, Mannelli M, Csako G, Walther MM, Brouwers FM \& Pacak K.

Pheochromocytoma catecholamine phenotypes and prediction of tumor size and location by use of plasma free metanephrines. Clinical Chemistry 200551 735-744. (doi:10.1373/clinchem. 2004.045484)

16 Zelinka T, Eisenhofer G \& Pacak K. Pheochromocytoma as a catecholamine producing tumor: implications for clinical practice. Stress 200710 195-203. (doi:10.1080/10253890701395896)

17 Eisenhofer G, Lenders JWM, Timmers H, Mannelli M, Grebe SK, Hofbauer LC, Bornstein SR, Tiebel O, Adams K, Bratslavsky G et al. Measurements of plasma methoxytyramine, normetanephrine, and metanephrine as discriminators of different hereditary forms of pheochromocytoma. Clinical Chemistry 201157 411-420. (doi:10.1373/clinchem.2010.153320)

18 Perry CG, Sawka AM, Singh R, Thabane L, Bajnarek J \& Young WF. The diagnostic efficacy of urinary fractionated metanephrines measured by tandem mass spectrometry in detection of pheochromocytoma. Clinical Endocrinology 200766 703-708. (doi:10.1111/j.1365-2265.2007.02805.x)

19 Eisenhofer G, Kopin IJ \& Goldstein DS. Catecholamine metabolism: a contemporary view with implications for physiology and medicine. Pharmacological Reviews 200456 331-349. (doi:10.1124/pr.56.3.1)

20 Ito T, Imai T, Kikumori T, Shibata A, Horiba T, Kobayashi H, Sawaki M, Watanabe R, Nakao A \& Kiuchi T. Adrenal incidentaloma: review of 197 patients and report of a drug-related false-positive urinary normetanephrine result. Surgery Today 200636 961-965. (doi:10.1007/s00595-006-3291-9)

21 Bouhanick B, Fauvel J \& Pont F. Biochemical misdiagnosis of pheochromocytoma in patients treated with sulfasalazine. JAMA 2010304 1898-1901. (doi:10.1001/jama.2010.1563)

22 Hoegerle S, Nitzsche E, Altehoefer C, Ghanem N, Manz T, Brink I, Reincke M, Moser E \& Neumann HPH. Pheochromocytomas: detection with 18 F DOPA whole body PET - initial results. Radiology 2002222 507-512. (doi:10.1148/ radiol.2222010622)

23 Lumachi F, Tregnaghi A, Zucchetta P, Cristina Marzola M, Cecchin D, Grassetto G \& Bui F. Sensitivity and positive predictive value of CT, MRI and 123I-MIBG scintigraphy in localizing pheochromocytomas: a prospective study. Nuclear Medicine Communications 200627 583-587. (doi:10.1097/00006231200607000-00006)

24 Luster M, Karges W, Zeich K, Pauls S, Verburg FA, Dralle H, Glatting G, Buck AK, Solbach C, Neumaier B et al. Clinical value of 18F-fluorodihydroxyphenylalanine positron emission tomography/ computed tomography (18F-DOPA PET/CT) for detecting pheochromocytoma. European Journal of Nuclear Medicine and Molecular Imaging 201037 484-493. (doi:10.1007/s00259009-1294-7)

25 Amar L \& Eisenhofer G. Diagnosing phaeochromocytoma/ paraganglioma in a patient presenting with critical illness: biochemistry versus imaging. Clinical Endocrinology 201583 298-302. (doi:10.1111/cen.12745)

26 Krajewska E, Toutounchi S, Fiszer P, Cieśla W, Pogorzelski R, Bednarczuk T, Cieszanowski A, Loń I \& Skórski M. Adrenal tumors diagnostics and the factual situation. Polski Przeglad Chirurgiczny 2012 84 208-213.

27 Bhatia KSS, Ismail MM, Sahdev A, Rockall AG, Hogarth K, Canizales A, Avril N, Monson JP, Grossman AB \& Reznek RH. 123I-metaiodobenzylguanidine (MIBG) scintigraphy for the detection of adrenal and extra-adrenal phaeochromocytomas: CT and MRI correlation. Clinical Endocrinology 200869 181-188. (doi:10.1111/ j.1365-2265.2008.03256.x)

28 Wiseman GA, Pacak K, O'Dorisio MS, Neumann DR, Waxman AD, Mankoff DA, Heiba SI, Serafini AN, Tumeh SS,
Khutoryansky $\mathrm{N}$ et al. Usefulness of 123I-MIBG scintigraphy in the evaluation of patients with known or suspected primary or metastatic pheochromocytoma or paraganglioma: results from a prospective multicenter trial. Journal of Nuclear Medicine 200950 1448-1454. (doi:10.2967/jnumed. 108.058701)

29 Jacobson AF, Deng H, Lombard J, Lessig HJ \& Black RR. 123I-metaiodobenzylguanidine scintigraphy for the detection of neuroblastoma and pheochromocytoma: results of a meta-analysis. Journal of Clinical Endocrinology and Metabolism 201095 2596-2606. (doi:10.1210/ jc.2009-2604)

30 Timmers HJLM, Taieb D \& Pacak K. Current and future anatomical and functional imaging approaches to pheochromocytoma and paraganglioma. Hormone and Metabolic Research 201244 367-372. (doi:10.1055/s-0031-1299712)

31 Timmers HJLM, Chen CC, Carrasquillo JA, Whatley M, Ling A, Havekes B, Eisenhofer G, Martiniova L, Adams KT \& Pacak K. Comparison of 18F-fluoro-L-DOPA, 18F-fluoro-deoxyglucose, and 18F-fluorodopamine PET and 123I-MIBG scintigraphy in the localization of pheochromocytoma and paraganglioma. Journal of Clinical Endocrinology and Metabolism 200994 4757-4767. (doi:10.1210/jc.2009-1248)

32 Barzon L, Sonino N, Fallo F, Palu G \& Boscaro M. Prevalence and natural history of adrenal incidentalomas. European Journal of Endocrinology 2003149 273-285. (doi:10.1530/eje.0.1490273)

33 Mansmann G, Lau J, Balk E, Rothberg M, Miyachi Y \& Bornstein SR. The clinically inapparent adrenal mass: update in diagnosis and management. Endocrine Reviews 200425 309-340. (doi:10.1210/ er.2002-0031)

34 Miettinen M, Fetsch JF, Sobin LH \& Lasota J. Gastrointestinal stromal tumors in patients with neurofibromatosis 1: a clinicopathologic and molecular genetic study of 45 cases. American Journal of Surgical Pathology 200630 90-96. (doi:10.1097/ 01.pas.0000176433.81079.bd)

35 Andersson J, Sihto H, Meis-Kindblom JM, Joensuu H, Nupponen N \& Kindblom L-G. NF1-associated gastrointestinal stromal tumors have unique clinical, phenotypic, and genotypic characteristics. American Journal of Surgical Pathology 200529 1170-1176. (doi:10.1097/ 01.pas.0000159775.77912.15)

36 Saha SB, Parmar R \& Mandal A. Small bowel obstruction in a neurofibromatosis patient - a rare presentation of Gastro-Intestinal Stromal Tumors (GISTs): case report and literature review. Indian Journal of Surgery $2013 \mathbf{7 5}$ 415-417. (doi:10.1007/s12262012-0746-7)

37 Kinoshita K, Hirota S, Isozaki K, Ohashi A, Nishida T, Kitamura Y, Shinomura Y \& Matsuzawa Y. Absence of c-kit gene mutations in gastrointestinal stromal tumours from neurofibromatosis type 1 patients. Journal of Pathology 2004202 80-85. (doi:10.1002/ path.1487)

38 Colleselli D \& Janetschek G. Current trends in partial adrenalectomy. Current Opinion in Urology 201525 89-94. (doi:10.1097/ MOU.0000000000000147)

39 Castinetti F, Qi X-P, Walz MK, Maia AL, Sansó G, Peczkowska M, Hasse-Lazar K, Links TP, Dvorakova S, Toledo RA et al. Outcomes of adrenal-sparing surgery or total adrenalectomy in phaeochromocytoma associated with multiple endocrine neoplasia type 2: an international retrospective population-based study. Lancet Oncology 201415 648-655. (doi:10.1016/S14702045(14)70154-8)

40 Cavallaro G, Letizia C, Polistena A \& De Toma G. Laparoscopic adrenal-sparing surgery: personal experience, review on technical aspects. Updates in Surgery 201163 35-38. (doi:10.1007/s13304011-0052-0)

41 Plouin P-F, Fitzgerald P, Rich T, Ayala-Ramirez M, Perrier ND, Baudin E \& Jimenez C. Metastatic pheochromocytoma and paraganglioma: focus on therapeutics. Hormone and 
Metabolic Research 201244 390-399. (doi:10.1055/ s-0031-1299707)

42 Lafont M, Fagour C, Haissaguerre M, Darancette G, Wagner T, Corcuff JB \& Tabarin A. Per-operative hemodynamic instability in normotensive patients with incidentally discovered pheochromocytomas. Journal of Clinical Endocrinology and Metabolism 2015100 417-421. (doi:10.1210/jc.2014-2998)
43 Chen H, Sippel RS, O'Dorisio MS, Vinik AI, Lloyd RV, Pacak K $\&$ North American Neuroendocrine Tumor Society (NANETS). The North American Neuroendocrine Tumor Society consensus guideline for the diagnosis and management of neuroendocrine tumors: pheochromocytoma, paraganglioma, and medullary thyroid cancer. Pancreas 201039 775-783. (doi:10.1097/ mpa.0b013e3181ebb4f0)

Received 15 March 2016

Revised version received 18 July 2016

Accepted 22 July 2016 